\title{
HEALTH CARE WORKERS' KNOWLEDDGE AND PERCEPTIONS ABOUT PHARMACOVIGILANCE AND ADVERSE DRUG REACTIONS REPORTING
}

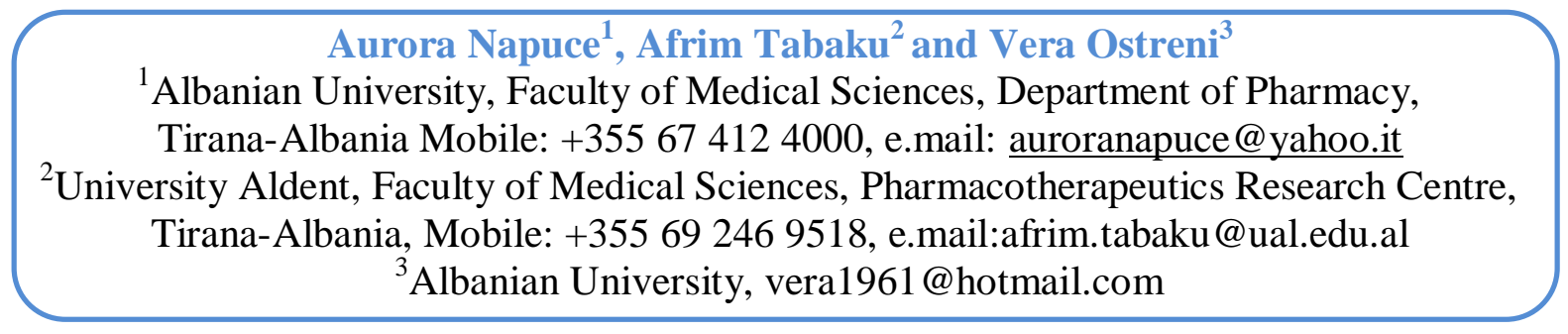

\begin{abstract}
Spontaneous adverse drug reaction (ADR) reporting is the cornerstone of pharmacovigilance. However, underreporting is a huge problem due to lack of reporting, especially in developing countries, where system of pharmacovigilance is not consolidated. A descriptive crosssectional survey is conducted on health professionals (physicians and nurses) working in Mother Theresa hospital in Tirana from September 2017 to June 2018 aimed to estimating the level of pharmacovigilance knowledge and practice of health professionals. A questionnaire which was suitable for assessing the basic Knowledge, Attitude and the Practice (KAP) of pharmacovigilance was designed and distributed among the physicians and nurses and filled up forms collected back and analyzed by using software SPSS 20. Out of 250 distributed forms 200 forms were received back, reflecting a response rate of $80 \%$. Results of this survey have shown that $80 \%$ of interviewed didn't know about the term of pharmacovigilance Over $90 \%$ of declaration of adverse drug reaction were made to the medical representatives and less than $10 \%$ to the National Pharmacovigilance Centre. $50 \%$ of physicians and $65 \%$ of nurses were not aware of the existence of National Pharmacovigilance Center. A wrong definition of pharmacovigilance term was given by $60 \%$ of physicians and $70 \%$ of nurses. Pharmacovigilance is a public health problem in Albania, with due to lack of good knowledge and practice of medical staff (physicians and nurses). There was a great need to create awareness among physicians and nurses to improve the knowledge about pharmacovigilance and the reporting of ADRs.
\end{abstract}

Keywords: Adverse drug reaction, Knowledge, attitude, and practices study, Pharmacovigilance, Spontaneous reporting

Correspondengig Author: Afrim Tabaku e.mail: afrimtabaku@yahoo.com

\section{INTRODUCTION}

Medicines during its normal therapeutic use has a potential to produce adverse drug reaction(s) (ADRs). ADR is defined according to WHO (2002) as any response to a drug which is noxious and unintended and occurs at doses normally used in man for prophylaxis, diagnosis or therapy of disease or the modification of physiological function. ADRs contribute to a significant number of morbidity and mortality all over the world (Oshikoya 2009: Lazarou et al., 1998; Classen et al., 1997; Beard 1992; Murphy 1993). It has been estimated that around 2.9-5.6\% of all hospital admissions are due to ADRs and as many as $35 \%$ of hospitalized patients experience an ADR during their hospitalization (Baniasadi et al, 
2008; Pirnmohamed et al, 2004; Ahmed 1997). In the UK, about 6.5\% of all admissions to hospitals are due to an ADR, and the overall fatality was $0.15 \%$ (Pirmohamed et al., 2004). A prospective study by Ahmed (1997) demonstrated that drug related problems report in Saudi Arabia showed that the mortality rate associated with ADRs in provincial hospitals was found to be $3.8 \%$ from the overall deaths in the general practice. In the United States, more than 100,000 deaths are attributed annually to serious adverse drug reactions (Lazarou et al., 1998). The economic burden of ADRs is also considerable; for example in the United States, annual total cost of $\$ 47.4$ billion for 8.7 million drug related admissions were reported (Millar 2001).

Recent estimates suggest ADRs to be the fourth major cause of death in the United States (Lazarou et al., 1998). In order to identify the offending drugs causing ADRs, several countries have initiated pharmacovigilance programs in the recent past. There are differences among countries and regions within countries in the occurrence of drug-related problems. This may be due to differences in diseases, prescribing practices, drug regulatory system, availability of drugs, genetics, diet habits and use of herbal remedies which may pose specific toxic problems. Because of these variation in drug response it has been recommended for every country to set up their own pharmacovigilance programs (WHO 2002) Most countries in the world have, therefore, established formal procedures to encourage healthcare professionals to report suspected ADRs they encounter in their clinical practice to their national drug regulatory authority or to the appropriate pharmaceutical manufacturer.

Many developed countries have strong pharmacovigilance systems. Good pharmacovigilance system will identify the risks and the risk factors in the shortest possible time so that harm can be avoided or minimized (WHO 2006). These systems among other use spontaneous reporting to collect and analyze adverse events associated with the use of drugs.

Although pharmacovigilance programs are successful in improving drug use patterns, underreporting of ADRs is felt as a major problem (Lee 2003). There is also strong evidence of significant and widespread under-reporting of ADRs to spontaneous reporting systems including serious or severe ADRs (Hazell et al, 2006). Under-reporting of ADRs is very common. It has been estimated that only $6-10 \%$ of all the ADRs are reported (Feely et al., 1990). One of the reasons for under-reporting might be a poor understanding of the healthcare professionals towards the existing pharmacovigilance program. In Malaysia, lack of awareness about the existence, function and purpose of national ADR reporting were the major reasons for under-reporting (Aziz et al, 2007). Researchers from Portugal found a strong association between attitudes associated with under-reporting (Herdeiro et al, 2005). In China, healthcare professionals had only a little basic knowledge of ADR and about the existing voluntary reporting system and were the major reasons for underreporting ( $\mathrm{Li}$ et al, 2004). In Nigeria, the commonest factors responsible for under-reporting were lack of knowledge on the availability of reporting forms and ignorance of the reporting procedure (Okezie et al, 2008). A recent systematic review reported knowledge and attitudes of health professionals to be strongly related with reporting of ADRs.

Physicians, pharmacists, dentists and nurses are in a position to play a major key role in pharmacovigilance programs (Ahmad 2003, Wysowski 2005) but under-reporting is very common, with an estimated median under-reporting rate of 94\% (defined as percentage of ADRs detected from intensive data collection that were not reported to relevant spontaneous reporting systems) (Hazell 2006).

Although pharmacovigilance programs are successful in improving drug use patterns, under reporting of ADRs is felt as a major problem (Zolezzis 2005) In order to improve the 
reporting rate, it is important to improve the Knowledge, Attitude and Practices (KAP) of the healthcare professionals regarding ADR reporting and Pharmacovigilance.

The Pharmacovigilance Center in Albania is established in 2011, so pharmacovigilance is still in its first steps and there exists very limited knowledge about this discipline. There is a lack of studies that address the knowledge, attitudes and perception of healthcare professionals toward the pharmacovigilance system and ADRs reporting. in this country. The aim of the present survey was to assess the knowledge and awareness of ADRs reporting and pharmacovigilance system among the healthcare professionals.

\section{MATERIAL AND METHODS}

A cross sectional study was carried out among the physicians and nurses working at the Mother Theresa Hospital University Center in Tirana, Albania from September 2017 to June 2018.. The questionnaires were distributed among the 125 physicians and 125 nurses. A total from 200 filled questionnaire were returned (94 physicians and 106 nurses) and thus response rate was $80 \%$. The self-administered questionnaire was used to assess the awareness of reporting of ADRs and pharmacovigilance among physicians and nurses. The questionnaire was structured to obtained demographics data of the participants, information about their knowledge of definition of pharmacovigilance, of ADR reporting, attitudes to reporting, factors that may influence reporting. The questionnaire included both open-ended and close-ended questions. The questionnaire after its preparation was reviewed by subject experts as regards the face validity, content validity and the relevance and comprehensiveness. The questionnaire was validated through a pilot study of 20 randomly selected physicians and nurses. The questionnaire was finalized after ambiguous and unsuitable questions were modified based on the result of pretest. The approval from the ethics committee was obtained before starting the study. Data analysis was performed using SPSS version 20 . The results were analyzed by using simple descriptive statistics involving frequencies, percentages, and proportions.

\section{RESULTS AND DISCUSSION}

Data on demographic characteristics and professional details of respondents are shown in graphs 1 and 2.

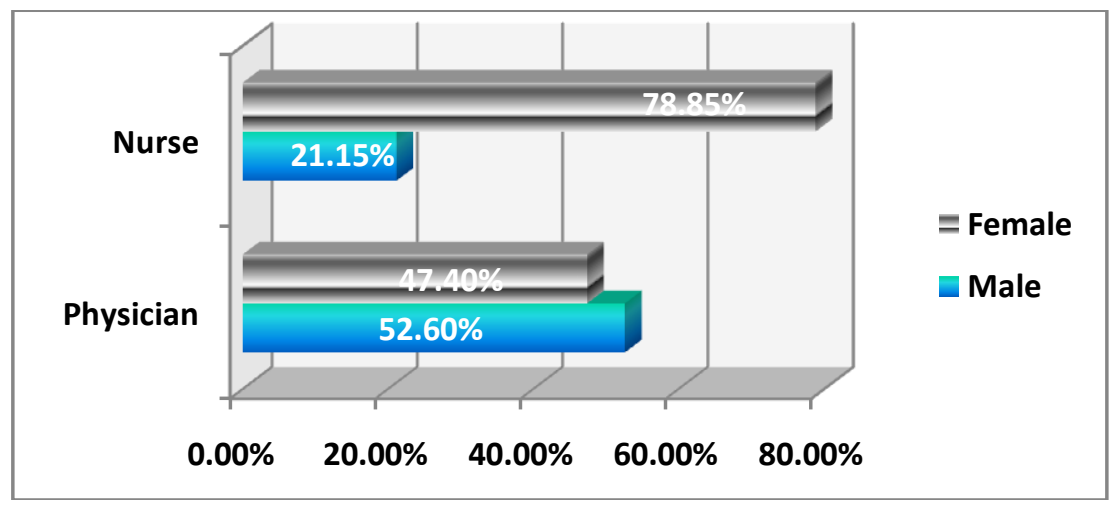


Graph 2: Years in profession

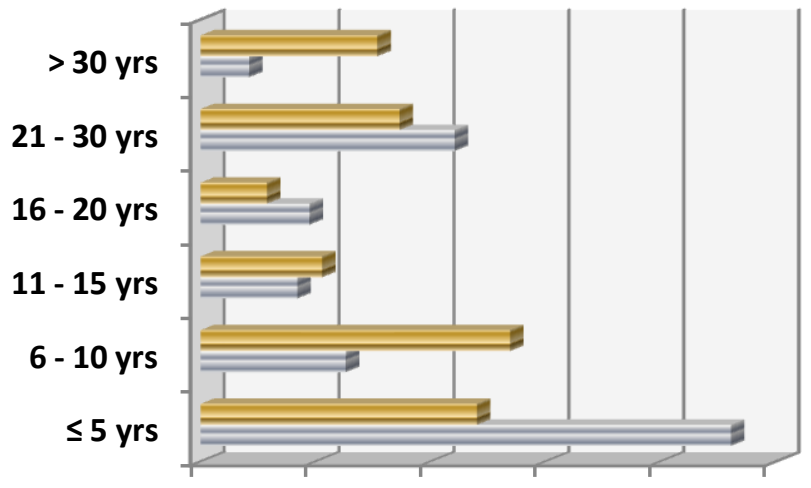

$=$ Nurse

$=$ Physician

$0.00 \% \quad 10.00 \% 20.00 \% 30.00 \%$ 40.00\% $50.00 \%$

A total of 250 questionnaires, equally by 125 questionnaires, were distributed among the physicians and nurses, and were returned 94 questionnaires $(75.2 \%)$ from physicians and 106 $(84.4 \%)$ were returned from nurses. The ratio female: male of medical workers that have filled the questionnaires was 52.60\%: $47.40 \%$ for physicians and had a average age of $39.86 \pm 11.22$ years, ranged from $23-68$ years, whereas for nurses the ratio female: male was $78.85 \%: 21.15 \%$ and the mean age of $35.55 \pm 11.47$ years, ranged from $22-61$ years. When grouped according to years of experience, about $45 \%$ of the physicians and $25 \%$ of nurses have up to five years worked.

\section{Knowledge on pharmacovigilance}

Data obtained from this survey have shown that $40.62 \%$ of physicians and $35.48 \%$ of nurses gave correct response regarding the definition of pharmacovigilance. $55.21 \%$ of physicians and $30.77 \%$ of nurses were aware that the most important purpose of pharmacovigilance is to identify safety of the drug, whereas regarding obligation for reporting of ADRs $86.31 \%$ and $97.11 \%$ of respectively healthcare professional agreed that ADR reporting is a professional obligation for them. $50.52 \%$ of physicians and $41.41 \%$ of nurses were aware regarding the existence of Center of Pharmacovigilance in Albania. 66.67\% of interviewed physicians and 20.94\% of nurses recognize the Albanian Agency for Medicinal Products and Medical Devices as the institution to which ADR of a medicinal product are to be reported.

Table 1 Definition of pharmacovigilance

\begin{tabular}{|l|l|l|}
\hline Define Pharmacovigilance & Physicians & Nurses \\
\hline $\begin{array}{l}\text { The science detecting the type and incidence of ADR after drug } \\
\text { is marketed }\end{array}$ & $47(48.96 \%)$ & $48(46.15 \%)$ \\
\hline The science of monitoring ADR's occurring in a Hospital & $5(5.21 \%)$ & $15(14.42 \%)$ \\
\hline $\begin{array}{l}\text { The process of improving the safety of the drug } \\
\text { The detection, assessment, understanding and prevention of advers } \\
\text { effects }\end{array}$ & $39(40.62 \%)$ & $37(35.58 \%)$ \\
\hline
\end{tabular}


Graph 5

Purpose of pharmacovigilance

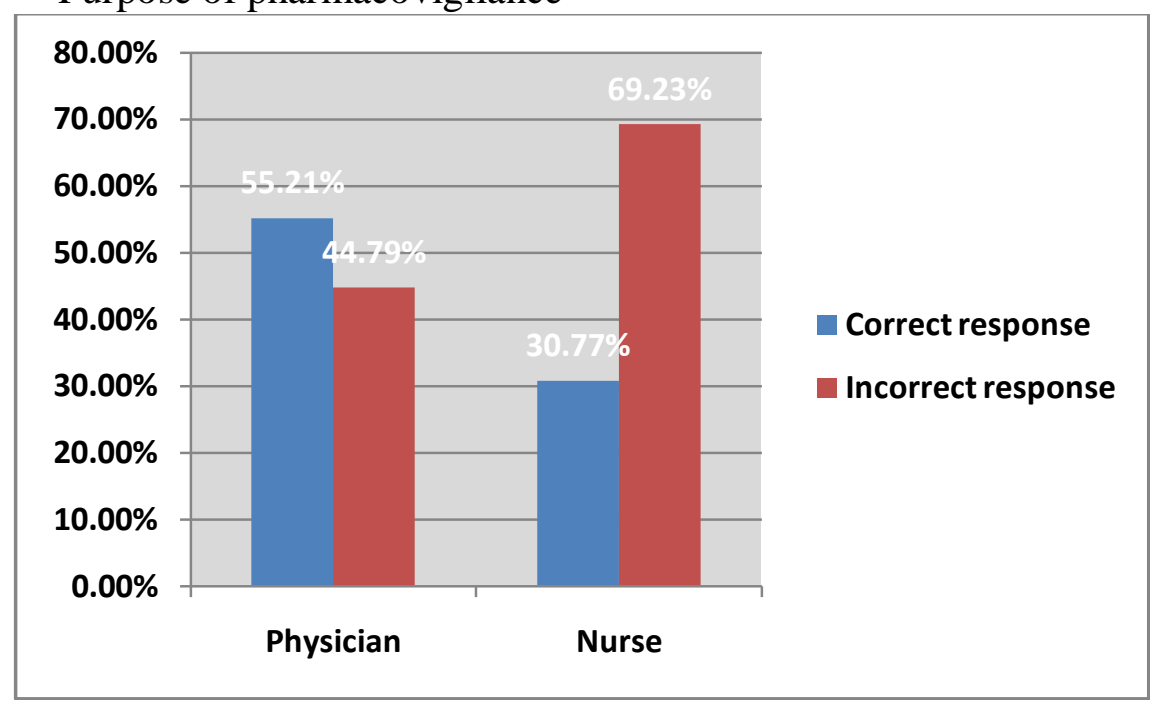

Results of this survey have shown that $40.62 \%$ of physicians and $35.58 \%$ of nurses gave correct response for definition of pharmacovigilance, whereas for the most important purpose of pharmacovigilance correct answer were $55.21 \%$ and $30.77 \%$ respectively.

\section{Attitude}

While assessing the pharmacovigilance related attitude of the healthcare professionals it was found that $97.11 \%$ of physicians and $86.31 \%$ of nurses agreed that reporting of ADR is necessary. There was strong agreement among the medical practitioners on the need to report ADR. Based on survey from Romania, majority of the medical practitioners strongly agreed ADR reporting is mandatory $60.1 \%$ (Paveliu et al., 2013), similar finding was obtained from UAE 66.7\% (John et al., 2012), Pakistan 80\% (Iffat et al., 2014), and from India 95\% (Adhikary et al., 2013) and $80.9 \%$ (Gupta and Udupa, 2011). In contrast, only one study from India had different finding where only $15.2 \%$ of the medical practitioners believed reporting ADR is compulsory (Pimpalkhute et al., 2012).

\section{Assessment of pharmacovigilance related practices}

Among the participants, $74.64 \%$ have experienced ADRs in patients and none of ADRs in reported at Center of Pharmacovigilance. $35.42 \%$ of physicians and $23.88 \%$ of nurses have knowledge for reporting of ADRs. Survey data indicated that doctors' practice on ADRs reporting is generally poor because many came across ADRs but did not take any action. In a study conducted in Nigeria $64.9 \%$ of medical practitioners said they have not come across ADR (Awodele et al., 2011), similar finding was obtained in Pakistan 65.6\% (Iffat bet al., 2014 and 50\% (Upadhyaya et al., 2012) in India.

\section{Reasons for underreporting}

The factors discouraging participants from reporting ADRs were uncertain of how to report $37.36 \%$, lack of time $5.67 \%$, forgetfulness $3.07 \%$, lack of feedback $12.45 \%$, unavailability of reporting form $44.33 \%$, ADRs was well known $8.59 \%$, etc.

In a survey conducted in UAE $71 \%$ of physicians suggested that lack knowledge of reporting procedure is major reason for under-reporting (John et al., 2012). Similar findings was obtained in India 70\% (Desai et al., 2011), and Nigeria 48.6\% (Adedeji et al., 2013). In another surveys ADR reporting was considered as time consuming, India 45\% (Sanghavi et al., 2013) and Netherland 35\% (Passier et al., 2009). In a survey conducted in Malaysia 
doctors felt that uncertainly about ADR discourage reporting 76.6\% (Agarwal et al., 2013), similar outcome was obtained in Sweden 75\% (Backstrom and Mjorndal, 2006), Romania 40.2\% (Paveliu et al., 2013) and India 30.9\% (Khan et al., 2013). In another survey carried out in Portugal $20 \%$ of physicians felt that ADR report will put their carrier at risk (Herdeiro et al., 2005), also in India 46.5\% (Kamtane and Jayawardhani, 2012)

It was found in this survey that about $70 \%$ of respondents do not know how to report ADRs. Similar findings have been reported in Northern India (Rehan et al. 2002), Italy (Cosentino et al. 1997) and China ( $\mathrm{Li}$ et al. 2004) were majority of the participants were having poor knowledge on ADR reporting, but different from the findings of other studies conducted at UK (Evans et al. 2006), Australia (Christopher et al. 2001) and Nigeria (Enwere et al. 2008) were adequate knowledge on how to report was identified among the healthcare professionals. It is a serious concern to realize that such a large proportion of the participants does not know how to report ADRs because this can delay signal detection and impact negatively on the public health. The present survey showed that in terms of knowledge by profession, nurses had lesser knowledge than doctors on ADR reporting. One possible explanation could be ADR reporting was initially regarded as a professional obligation for other profession except nurses. These results suggest that the role of nurses in ADR reporting should be clarified and that they should start to be given an open access to reporting (Hall et al. 1995), as they are often the first contact with patients.

Overall in the current survey, only a part of physicians knew how to report ADRs and answered correctly that life threatening reactions are one of the reactions that need to be reported. These findings were also observed on the studies conducted by van Grootheest et al. (2002) and Ekman et al. (2009) were majority of the doctors were having knowledge on the kind of reactions that have to be reported. Surprisingly, more than $73 \%$ of the physicians and $87 \%$ of nurses were not aware of the format of reporting on this survey. This is consistent with the findings of a study conducted by Oshikoya et al. (2009) in Nigeria whose results also revealed majority of the physicians were not aware of the format of reporting. This is clearly an indication that awareness on ADR reporting will be very essential among the physicians and nurses even though some of them reported to have knowledge on ADR reporting.

Overall, the attitude of healthcare professionals in this study was positive. The survey found that majority of the respondents felt that reporting of ADR can benefit the public health, one report can make a difference and filling of the ADR yellow form is useful. It was good to notice that majority of the participants in this survey considered ADR reporting as important.

Results of this survey shown that physicians and nurses have a negative attitude regarding reporting of ADRs. Similar results are obtained in other countries like Canada (Golafshani, 2003), Nigeria (Enwere et al. 2008) and Germany (Hasford et al. 2002) physicians were reported to have a negative attitude towards ADR reporting because they believed that observing ADRs raises no concern and that there is no need to report them. The finding of the studies conducted at Australia (Evans et al. 2006), Iran (Hajebi et al. 2010) and UK (Wilson et al. 2008) also showed that nurses had a positive attitude towards ADR reporting because they felt that all ADRs are valuable and should be reported.

In clinical practice, over $74 \%$ of healthcare professionals in the current survey had at some point diagnosed ADRs. However, none of those who diagnosed ADRs did not report them to pharmacovigilance reporting center and those who reported claimed to have reported the suspected ADRs to the pharmaceutical companies, hospital and physicians. It is likely that most of the reported ADR cases were actually not formal written reports, but oral reports made during an informal conversation hence they were not reported to any reporting place. This high rate of underreporting of ADRs to the reporting centers was also observed among and physicians at Portugal (Davis et al. 1999), USA (Belton et al. 1995) and Nigeria (Enwere 
et al. 2008). These findings could be the results of unavailability of reporting forms at the hospitals and also inadequate knowledge on the existence of the pharmacovigilance centres.

The findings of a study conducted at Iran (Hajebi et al. 2010) were that $70 \%$ of the nurses had never encountered an ADR when compared to a similar study in China (Li et al. 2004), were $85 \%$ of nurses had encountered with an ADR before. Regarding, the place where ADR are supposed to be send, nurses had a different insight on that. The findings made by Hajebi et al. (2010) were that, most nurses used to send their reports to physicians in the ward $(56 \%)$, and head nurse $(26 \%)$

It was found in this survey that there are main reasons that might have contributed towards under-reporting of ADRs among the participants such as uncertain on how to report lack of feedback and unavailability of reporting forms and lack of time, This is consistent with other studies conducted among physicians at Nigeria (Enwere et al. 2008) and US (Belton et al. 1995).. From these results, it is clear that respondents did not know the procedure for the ADR reporting and monitoring.

The limitations of this survey the limited number of physicians and nurses were participated although, the response rate was satisfactory. This survey was also conducted in one setting and views of healthcare professionals from other similar setting could not be explored.

\section{CONCLUSION}

The results of our survey indicate that majority of the healthcare professionals had a poor knowledge and attitude about pharmacovigilance. There was a huge gap between the ADR experienced and ADR reported by the healthcare professionals. It is a urgent need to improve physicians and nurses attitude towards ADR reporting.

\section{REFERENCES}

1. The World Health Organization, 2002. Safety of medicines: A guide to detecting and reporting adverse drug reactions, Geneva

2. Oshikoya KA, Awobusuyi JO. Perceptions of doctors to adverse drug reaction reporting in a teaching hospital in Lagos, Nigeria. BMC Clin Pharmacol 2009;9:15-20.

3. Lazarou, J., Pomeranz, B.H., Corey, P.N., 1998. The incidence of adverse drug reactions in hospitalized patients-a meta- analysis of prospective studies. JAMA 279, 1200-1205

4. Classen, D.C., Pestonik, S.L., Evans, R.S., Lioyd, J.F., Burke, J.P., 1997. Adverse drug events in hospitalized patient- excess length of stay, extra cost and attributable mortality. JAMA 277, 301-306.

5. Beard K Adverse reactions as a cause of hospital admission in the aged. Drugs Aging. 1992;2(4):356-367.

6. Murphy BM, Frigo LC. Development, implementation, and results of a successful multidisciplinary adverse drug reaction reporting program in a university teaching hospital. Hosp Pharm. 1993;28(12):1199-204,1240.

7. Baniasadi S, Fahimi F, Shalviri G. Developing an adverse drug reaction reporting system at a teaching hospital. Basic Clin Pharmacol Toxicol. 2008;102:408-11.

8. Pirmohamed, M., James, S., Meakin, S., Green, C., Scott, A.K., Walley, T.J., Keith Farrar, K., Park, B.K., Breckenridge, A.M.Adverse drug reactions as cause of admission to hospital: prospective analysis of 18820 patients. BMJ 2004, 329, 15-19

9. Ahmed, M.el-B., 1997. Drug-associated admissions to a district hospital in Saudi Arabia. J. Clin. Pharm. Ther. 22, 61-66 
10. Lazarou J, Pomeranz BH, Corey PN. Incidence of adverse drug reactions in hospitalized patients: a meta-analysis of prospective studies. JAMA. 1998;279(15):1200-1205.

11. Millar JS. Consultations owing to adverse drug reactions in a single practice. $\mathrm{Br} \mathrm{J}$ Gen Pract. 2001;51(463):130-1

12. WHO The Safety of Medicines in Public Health Programmes: pharmacovigilance an Essential Tool. Geneva: WHO;2006.

13. Lee A, Thomas SHL. Adverse drug reactions In: Walker R and Edward C. Clinical pharmacy and Therapeutics. $3^{\text {rd }}$ edition Churchill Livingstone, 2003, p.33-46.

14. Hazell L, Shakir SA. Under-reporting of adverse drug reactions: a systematic review. Drug Saf. 2006;29(5):385-396.

15. Feely, J., Moriarty, S., O'Connor, P., 1990. Stimulating the reporting of an adverse drug reaction by using a fee. Br. Med. J. 300, 22-23.

16. Aziz Z, Siang TC, Badarudin NS. Reporting of adverse drug reactions: predictors of under-reporting in Malaysia. Pharmacoepidemiol Drug Saf. 2007;16(2):223-228.

17. Herdeiro MT, Figueiras A, Polónia J, Gestal-Otero JJ. Physicians' attitudes and adverse drug reaction reporting: a casecontrol study in Portugal. Drug Saf. 2005;28(9):825-833.

18. Li,Q, Zhang SM, Chen HT, Fang SP, Yu X, Liu D, Shi LY, Zeng FD. Awareness and attitudes of healthcare professionals in Wuhan, China to the reporting of adverse drug reactions. Chin Med J (Engl). 2004;117:856-861.

19. Okezie E O, Olufunmilayo F. Adverse drug reactions reporting by physicians in Ibadan, Nigeria. Pharmacoepidemiol Drug Saf. 2008;17(5):517-522.

20. Ahmad SR. Adverse drug event monitoring at the Food and Drug Administration: your report can make a difference. J Gen Intern Med 2003; 18:57-60.

21. Wysowski DK, Swartz L. Adverse drug event surveillance and drug withdrawals in the United States, 1969-2002: the importance of reporting suspected reactions. Arch Intern Med. 2005;165:1363-69.

22. Zolezzis $M$ and Parsotam N. Adverse drug reaction reporting in New Zealand: implications for pharmacists. Ther Clin Risk Manag. 2005; 3: 181-188

23. Paveliu MS, Bengea-Luculescu S, Toma M, Paveliu SF. Perception on Adverse Drug Reaction Reporting by Physicians Working in Southern Romania. J ClinMed, 2013; 8(1): $17-25$

24. John LJ, Arifulla M, Cheriathu J, Sreedharan J. Reporting of Adverse Drug Reactions: a study among Clinicians. J Appl Pharm Sci, 2012; 2 (6): 135-139.

25. Iffat W, Shakeel S, Rahim N, Anjum F, Neesar S, Ghayas S. Pakistani physicians' knowledge and attitude towards reporting adverse drug reactions. African Journal of Pharmacy and Pharmacology, 2014; 8 (14): 379-385.

26. Gupta P, Udupa A. Adverse Drug Reaction Reporting and Pharmacovigilance: Knowledge, Attitudes and Perceptions amongst Resident Doctors. J Pharm Sci Res, 2011; 3(2): 1064-1069.

27. Pimpalkhute SA, Jaiswal KM, Sontakke SD, Bajait CS, Gaikwad A. Evaluation of awareness about pharmacovigilance and adverse drug reaction monitoring in resident doctors of a tertiary care teaching hospital. Indian J Med Sci, 2012, 1; 66 (3 \& 4): 55-61.

28. Upadhyaya P, Seth V, Moghe VV, Sharma M, Ahmed M. Knowledge of adverse drug reaction reporting in first year postgraduate doctors in a medical college. Ther Clin Risk Manag, 2012; 8: 307-312.

29. Desai CK, Iyer G, Panchal J, Shah S, Dikshit RK. An evaluation of knowledge, attitude, and practice of adverse drug reaction reporting among prescribers at a tertiary care hospital. Perspect Clin Res, 2011; 2 (4): 129-136. 
30. Adedeji WA, Ibrahem WA, Fehintola FA. Attitude and Practice of Doctors toward Adverse Drug Reactions (ADRs) Reporting In A Nigerian Tertiary Health Facility. Ann Ibd Pg Med, 2013; 1(2): 77-80.

31. Sanghavi DR, Dhande PP, Pandit VA. Perception of pharmacovigilance among doctors in a tertiary care hospital: Influence of an interventional lecture. Int J Risk Saf Med, 2013; 25 (4): 197-204

32. Passier A, Napel MT, van Grootheest K, van Puijenbroek E. Reporting of Adverse Drug Reactions by General Practitioners. Drug Saf, 2009; 32 (10): 851-858.

33. Agarwal R, Daher AM, Ismail NM. Knowledge, Practices and Attitudes Towards Adverse Drug Reaction Reporting by Private Practitioners from Klang Valley in Malaysia. Malays J Med Sci, 2013; 20(2): 52-61

34. Backstrom M, Mjorndal T. A small economic inducement to stimulate increased reporting of adverse drug reactions - a way of dealing with an old problem? Eur J Clin Pharmacol, 2006; 62: 381-385

35. Khan SA, Goyal C, Chandel N, Rafi M. Knowledge, attitudes, and practice of doctors to adverse drug reaction reporting in a teaching hospital in India: An observational study. Journal of Natural Science, Biology, and Medicine, 2013; 4(1): 191-196

36. Kamtane RA, Jayawardhani V. Knowledge, attitude and perception of physicians towards adverse drug reaction (ADR) reporting: a pharmacoepidemiological study. Asian J Pharm Clin Res, 2012; 5(3): 210-214

37. Rehan HS, Vasudev K and Tripathi CD. 2002. Adverse drug reaction monitoring:knowledge, attitude and practices of medical students and prescribers. Natl Med J India; 15: 24-26.

38. Cosentino M, Leoni O, Banfi F, Leechini S and Frigo G. 1997. Attitudes to adverse drug reaction reporting by medical practitioners in a Northern Italian district.Pharmacol Res; 35 (2): 85-88.

39. Evans SM, Berry JG, Smith BJ, Esterman A, Selim P, O'Shaughnessy J and DeWit M. Attitudes and barriers to incident reporting: a collaborative hospital study. Quality and Safety in Health Care; 2006. 15 (1): 39-43.

40. Christopher FG, David RM, Philip HR and Munir P. 2001. Attitudes and knowledge of hospital pharmacists to adverse drug reaction reporting. Br J Clin Pharmacol; 51 (1): 8186

41. Enwere O.O and Fawole OI. 2008. Adverse drug reactions reporting by physicians in Ibadan, Nigeria. Pharmacoepidemiol Drug Safe; 17: 517-522

42. Hall M, McCormack P, Arthurs N and Feely J. 1995. The spontaneous reporting of adverse drug reactions by nurses. Br J Clin Pharmacol; 40: 173-175.

43. van Grootheest AC, Mes K and de Jong-van den Berg LTW. 2002. Attitudes of community pharmacists in The Netherlands towards adverse drug reaction reporting. Int J Pharm Pract; 10 (4): 267-272

44. Ekman E and Bäckström M. 2009. Attitudes among hospital physicians to the reporting of adverse drug reactions in Sweden. Eur J Clin Pharmacol; 65: 43-46

45. Golafshani N. 2003. Understanding Reliability and Validity in Qualitative Research. University of Toronto, Toronto, Ontario, Canada. The Qualitative Report; 8(4): 597- 607.

46. Hasford J, Goettler M, Munter KH and Muller-Oerlinghausen B. 2002. Physicians' knowledge and attitudes regarding the spontaneous reporting system for adverse drug reactions. J. Clin. Epidemiol; 55: 945-950.

47. Hajebi G, Mortaxavi S, Salemzadeh J and Zian A. 2010. A Survey of Knowledge, Attitude and Practice of Nurses towards Pharamacovigilance in Taleqani Hospital. 
School of Pharmacy, Shaheed Beheshti University of Medical Sciences, Tehran, Iran. Iranian Journal of Pharmaceutical Research; 9(2): 199-206.

48. Wilson B, Bekke H, Fylan F. 2008. Reporting of Clinical Adverse Events Scale: A measure of doctor and nurse attitudes to adverse event reporting. Quality \& Safety in Health Care; 17(5): 364-367

49. Davis S, Coulson RA and Wood SM. 1999. Adverse drug reaction reporting by hospital pharmacists: the first year. Pharm; 262: 366-367

50. Belton KJ, Lewis SC, Payne S, Rawlins MD, Wood SM. 1995. Attitudinal survey of adverse drug reaction reporting by medical practitioners in the United Kingdom. $\mathrm{Br} J$ clin Pharmac; 39: 223-226 